DOI: 10.20472/IAC.2018.042.011

TIGIST GEBREHIWOT

University of South Africa, South Africa

\title{
THE CHALLENGE FOR AFRICA TO TRANSITION INTO KNOWLEDGE ECONOMY
}

\begin{abstract}
:
The study is written with the purpose of answering three basic questions: Firstly, how Africa implement the appropriate policy, which is relevant to its socio-economic contexts in creating inclusive economic growth? Secondly, how the educational programme incorporates traditional knowledge (TK) into the mainstream in recognising the importance of these pieces of knowledge to the people? Thirdly, what comprises an appropriate knowledge management in building a knowledge economy in Africa?

The analysis of the study deals with the various challenges facing Africa transition to a knowledge economy. The significance of the study is to address Africa's overlooked and neglected knowledge produced locally from an institution and informal sectors which has a detrimental effect on building an inclusive economy. To resolve the issue, it is argued that appropriate reform in the structure administering knowledge is necessary for creating opportunities for individuals in building a network of innovators in society. The emerging understanding of knowledge economy also will be utilised to find the most appropriate solutions in this regard.

It is, therefore, this study will explore using descriptive approach to qualitative research, multi-disciplinary in nature, the management, the law, and economics by building bridges to the main disciplines working jointly to move beyond discipline specifics approach to address the issue. Both a desk and data-based approach utilising qualitative tools will be used in conducting this study.
\end{abstract}

\section{Keywords:}

Africa

Economy

Intellectual Property

Management

Traditional Knowledge 